\title{
PLANT HORMONES IN MARINE PHYTO- PLANKTON, ZOOPLANKTON AND SEA WATER
}

\author{
By Joyce A. BENTLey \\ Marine Laboratory, Aberdeen, Scotland
}

(Text-figs. I-4)

Studies by many workers on the subtle ecological relationships of marine organisms suggest that the distribution of these organisms may be controlled, at least in part, by trace organic substances in their environment. These substances may range from 'toxins to vitamins and hormones' (Lucas, 1955). Saunders (1957) has reviewed the interrelations of dissolved organic matter and phytoplankton and considered the possible roles of organic metabolites in the growth of the algae. The presence of several vitamins, for example, $\mathrm{B}_{12}$, thiamin, niacin and biotin, has been demonstrated in natural waters, but the possible occurrence of plant hormones has not previously been considered.

Work is in progress at Aberdeen on the production by algae of plant hormones of the auxin type, and detection of these auxins in algal media. Auxins are hormones which promote cell enlargement in plants. All the known auxins are indole compounds. This paper reports results of an examination of marine phytoplankton and sea water.

Many of the indole compounds known to be concerned in the bio-synthesis or degradation of indole auxins in the higher plants also occur in animals. For this reason it was decided to examine also zooplankton.

\section{MATERIALS}

The following materials have been examined:

\section{Plankton}

Marine phytoplankton and zooplankton collected by the fisheries research ships of the Department of Agriculture and Fisheries for Scotland was treated immediately on collecting with half its volume of ethanol, and stored in the deep-freeze or freeze-dried on reaching the laboratory.

Details of the phytoplankton samples, which consisted predominantly of diatoms, are given in Table I. In addition to the species listed in Table I, a few protozoa, silico-flagellates, small copepods and faecal pellets were present in sample I, a few faecal pellets in sample II and a few dinoflagellates in all three samples. 


\begin{tabular}{|c|c|c|c|c|}
\hline \multirow[b]{2}{*}{ Species } & \multicolumn{4}{|c|}{ Cells/litre } \\
\hline & I & II A & II B & III \\
\hline Leptocylindrus danicus & 120 & - & 150 & - \\
\hline Chaetoceros debilis & 120 & I95 & 750 & - \\
\hline C. decipiens & 105 & 135 & 1350 & - \\
\hline C. convolutus & - & - & 600 & - \\
\hline Thalassiosira gravida & 75 & I5 & - & - \\
\hline Guinardia flaccida & 45 & - & - & - \\
\hline Nitzschia seriata & 45 & 45 & 1500 & 1080 \\
\hline Coscinodiscus concinnus & 45 & - & - & - \\
\hline Thalassiothrix longissima & 45 & - & - & - \\
\hline T. nitzschioides & 30 & - & - & - \\
\hline $\begin{array}{l}\text { Rhizosolenia hebetata } \\
\text { (semispina) }\end{array}$ & - & 90 & 2700 & 一 \\
\hline Rhizosolenia styliformis & - & - & - & 405 \\
\hline
\end{tabular}

All hauls were by vertical standard net. Trawling positions were as follows: sample I, $60^{\circ} 35^{\prime}$ N., $3^{\circ} 12^{\prime}$ E. I4. iv. 57 ; II A $57^{\circ} 00^{\prime}$ N., $I^{\circ} 00^{\circ}$ W. 3 I. v. 57 ; II B $66^{\circ} 47^{\prime}$ N., I $6^{\circ} 27^{\prime}$ W. 18. vii. 57 ; III, $60^{\circ} 31^{\prime}$ N., $0^{\circ} 40^{\prime}$ W. 8 . vii. $58 ; 59^{\circ} 3^{\prime}$ N., $2^{\circ}$ I $5^{\prime}$ W. II. vii. 58.

Zooplankton sample I consisted predominantly of Copepoda (Temora, Calanus, stages I-IV and Para/Pseudo-calanus) and sample II predominantly of a mollusc, Spiratella (Limacina) retroversa. The trawling positions were as follows: sample I, $55^{\circ} 5^{\frac{1}{2}^{\prime}} \mathrm{N} .5^{\circ} 2^{\prime}$ W., 2 May $195^{8}$; sample II, $6 \mathrm{I}^{\circ} \mathrm{I}^{\prime} \mathrm{N}$, I0 $0^{\prime}$ W., Io July $195^{\circ}$.

Sea water

(I) I $101 .$, from 60 miles off-shore ( $57^{\circ} \mathrm{o}^{\prime} \mathrm{N} ., 0^{\circ} 30^{\prime} \mathrm{E}$.).

(II) 200 1., inshore sea water collected along the east coast of Scotland just south of Aberdeen.

\section{EXPERIMENTAL TECHNIQUES}

Slightly different extraction techniques were used with the different materials, and full details are given below. Attention is concentrated in this paper on the following fractions: (I) the acidic ether-soluble fraction (EA fraction), which would contain 3 -indolylacetic acid (IAA) and most of the known auxins if present; (2) the acidic ether-soluble substances derived from the hydrolysed aqueous ether-insoluble fraction (SA fraction); and (3) the corresponding neutral fractions (EN and $\mathrm{SN}$ ).

Some explanation of the reasons for examining the second set of fractions may be desirable. Recent work on plant growth hormones has shown that significant amounts of biological activity occur in the aqueous, ether-insoluble fractions of plant extracts, a fact which is of considerable interest, as the activity cannot be explained in terms of any of the known hormones. It was important therefore to analyse this fraction. Unfortunately, a direct examination is difficult, because large quantities of pigments, carbohydrates, amino acids and other substances, which may interfere with the bio-assays, are present. The following procedure was therefore adopted. 
From an analysis of previous work on the aqueous, ether-insoluble hormones it is possible that these substances are unstable auxin complexes which yield ether-soluble hormones on treatment with acid or alkali (Bentley, I960a). Accordingly, it was decided to treat the ether-insoluble fraction with alkali and look for any ether-soluble hormones produced. If any were found, they would be much more amenable to examination than substances in the aqueous ether-insoluble fraction, and it was hoped that any results obtained with them would help to shed light on their non-ether-soluble precursors. This fraction is referred to as the saponified fraction $(\mathrm{SA}=$ saponified acidic; $\mathrm{SN}=$ saponified neutral).

\section{Phytoplankton sample I}

\section{Detailed extraction techniques}

The material, which had been stored in the deep-freeze without filtration, was acidified to $\mathrm{pH} 5^{\circ} \mathrm{O}$ and stirred for $30 \mathrm{~min}$ with $500 \mathrm{ml}$. absolute ethanol. The mixture was filtered through paper pulp and the alcohol extract neutralized. The alcohol was removed under vacuum leaving $70 \mathrm{ml}$. aqueous extract. This was re-acidified to $\mathrm{pH}_{5}^{\circ} \mathrm{O}$ and extracted with ether. The ether extract was divided into acidic (EA) and neutral (EN) fractions, using $5 \% \mathrm{NaHCO}_{3}$. The aqueous, non-ether soluble material, was saponified with $\mathrm{N}-\mathrm{NaOH}$ for $30 \mathrm{~min}$ at $\mathrm{I} 5 \mathrm{lb}$. pressure, acidified and extracted with ether. This saponified extract was also separated into acidic (SA) and neutral (SN) fractions.

\section{Phytoplankton sample II}

The samples were freeze-dried on arrival in the laboratory (dry weight $5.4 \mathrm{~g}$ ). A little water was added, the $\mathrm{pH}$ adjusted to 5.0 and the mixture stirred for $30 \mathrm{~min}$ with two lots of $100 \mathrm{ml}$. chloroform. The material was filtered and separated, the chloroform fraction washed free of $\mathrm{HCl}$, evaporated to dryness and extracted with light petroleum $40-60^{\circ} \mathrm{C}$ to remove fatty materials. The petroleum fraction was rejected. Extraction with three lots of methanol followed, the methanol extract evaporated to dryness, the residue taken up in ether and split into acidic (EA) and neutral (EN) fractions. The aqueous non-chloroform soluble fraction was extracted with petroleum, then saponified as sample I and split into acidic (SA) and neutral (SN) fractions.

\section{Zooplankton samples I and II}

The material was extracted with $80 \%$ ethanol in a Waring blendor at $\mathrm{pH}_{4}{ }^{\circ}$, filtered and $\mathrm{pH}$ adjusted to $7^{\circ} 0$. The alcohol was removed under vacuum, the extract re-acidified $\left(\mathrm{pH}^{\circ} \mathrm{O}^{\circ}\right)$ and extracted first with $40-60^{\circ} \mathrm{C}$ light petroleum, then with ether. The ether solution was split into acidic (EA) and neutral (EN) fractions. The aqueous non-ether soluble fraction was saponified and split into acidic (SA) and neutral (SN) fractions. 


\section{Sea water}

The samples were filtered, acidified to $\mathrm{pH} 5.0$ and extracted by stirring for I h with freshly distilled chloroform. The chloroform was separated off, distilled in vacuo and the residues extracted with ether. The ether from sample II was separated into acidic (EA) and neutral (EN) fractions. It was not possible to work with the aqueous non-ether soluble fractions because of their large volumes, and because of the high concentration of salts.

\section{Chromatography}

Ether extracts were evaporated to dryness on a freeze-drier and the residues dissolved in a few drops of ethanol for loading on to chromatograms. Extracts were usually purified by preliminary paper chromatography using water as eluant and applying the extracts as a broad strip on the starting line; the pigments remained on the starting line, which was rejected. The remainder of the paper was flushed with ethanol and the recovered material chromatographed in iso-propanol:water:ammonia (sp.gr. o.88) (IO:I:I), or water. The ammoniacal iso-propanol mixture is widely used in auxin chromatography, as it has been found to give good separation of acidic auxins (Stowe \& Thimann, 1954). It has the disadvantage that the ammonia may cause breakdown of unstable compounds with production of artifacts (Bentley, $1958 b, 1960 b$ ), but it was felt advisable to use it here for the purposes of comparison with earlier work on plant extracts. Water, which was also used, is a neutral innocuous solvent in which the extracts run very quickly, thus minimizing the possibility of breakdown of compounds during chromatography. It was used as a check on the number of active zones obtained in the ammoniacal iso-propanol. It has the disadvantage that it does not give good compact spots suitable for colour tests. Some experiments were also tried using iso-propanol-water-acetic acid, but under these conditions no separation of active zones was achieved and activity was detected only at the solvent front. Acidic solvent systems were not therefore suitable. Chromatography was carried out in a constant temperature room at $15^{\circ} \mathrm{C}$. Chromatograms were examined under filtered ultra-violet light ( $2537 \AA$ transmitted) and used either for indole colour tests or bio-assays. The reagents used for colour tests were Ehrlich ( $p$-dimethyl aminobenzaldehyde), Salkowski and nitrous/nitric acid, using the techniques of Jepson (1958). Chromatograms to be bio-assayed were cut into ten equal portions and the portions eluted with I ml. water for testing. 3-Indolylacetic acid (IAA) and 3-indolyl-acetonitrile (IAN) were run as marker spots.

\section{Assay technique}

The Avena coleoptile straight-growth method, which is a measure of auxin activity in cell-enlargement, was used. Io $\mathrm{mm}$ lengths of Avena coleoptiles are suspended in the solutions to be tested, and the increase in 
lengths measured after $24 \mathrm{~h}$. The tissues grow by cell-enlargement. I \% sucrose and phosphate-citrate buffer $\left(\mathrm{IO}^{-2} \mathrm{M} \mathrm{K}_{2} \mathrm{HPO}_{4}\right.$ and $0.5 \times 10^{-2} \mathrm{M}$ citric acid) at $\mathrm{pH} 5^{\circ} \mathrm{O}$ is used as a basic medium. For full details of the assay method see Bentley \& Housley (1954). The test is specific for auxins. Other growth substances, e.g. vitamins and gibberellins, are virtually inactive. All the chromatography papers used in the bio-assays were washed in water and acetone before bio-assay, to remove impurities. Blank chromatograms, loaded with ether or alcohol but without extracts, were frequently developed and bio-assayed, and showed no biological activity.

\section{RESULTS}

\section{Marine phytoplankton}

There is an active zone $(\mathrm{Z})$ on the EA chromatograms and hints of activity at two less mobile zones (X and Y, Fig. I A). There are also two active zones in the SA fraction (Fig. I B), from which all the ether-soluble hormones had been removed before saponification. Several positive Ehrlich colours were obtained with the SA fraction, as indicated, but none with the EA fraction. For the sake of clarity, the three zones of activity in both the EA and the SA fractions in all the species examined have been called $\mathrm{X}, \mathrm{Y}$ and $\mathrm{Z}$, as indicated on the figures. This is because they show certain points of resemblance with auxins located in other plant materials and labelled $\mathrm{X}, \mathrm{Y}$ and $\mathrm{Z}$. This work is considered later in this section.

Three zones of activity can also be located in the SA fraction of sample II (Fig. I C). It is frequently found that sometimes only one zone (X) can be located; sometimes this can be resolved into two zones (X and Y). These separations probably depend on small differences in conditions of chromatography. A pink (or purple) Ehrlich reaction at $R_{f} 0 . \mathrm{I}-0.2$ has been obtained with all the SA samples examined, as shown in Figs. I A and B. This colour reaction indicates the presence of an indole compound. The SA fraction of sample III gave exactly similar results to Fig. I C, with three clear-cut zones, $\mathrm{X}, \mathrm{Y}$ and $\mathrm{Z}$. Thus, it seems that there are at least two, and often three active compounds in the SA fractions of varied samples of phytoplankton, indicating that these compounds are possibly involved in basic metabolism common to a range of species.

It has been thought in the past that the plant hormones were all acidic in nature. However, evidence is accumulating that there are also neutral auxins. Fig. I D shows that there is activity in the EN fraction of sample II, though this has not resolved into clear-cut zones. Moreover, it is not always obtained, suggesting that, when it does occur, it comes from neutral precursors, depending on the conditions of chromatography. Figs. IE and $\mathrm{F}$ illustrate activity found in the SN zones of samples I and II, respectively. Again, this activity is not always obtained and activity in specific zones is not reproducible. 

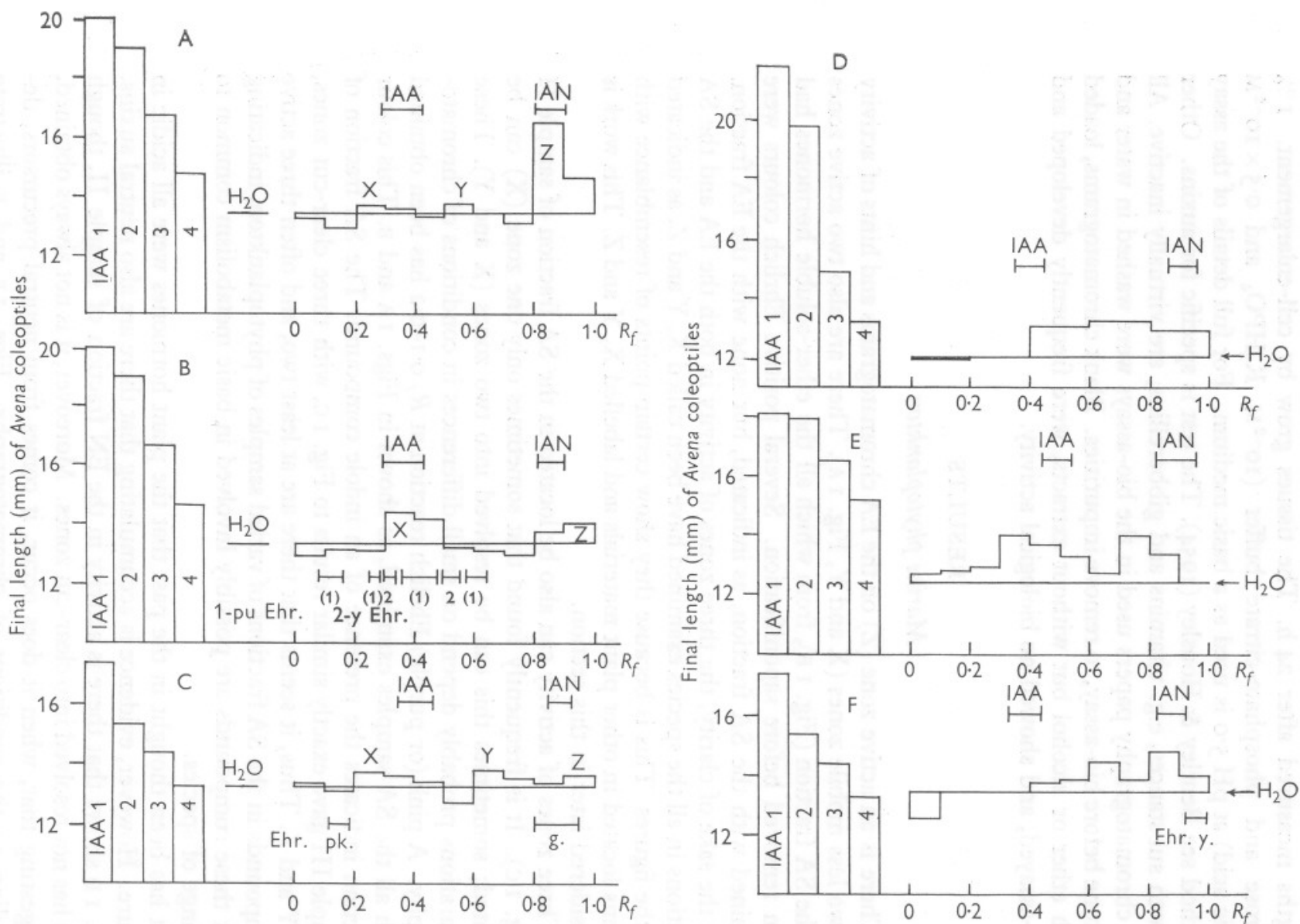

Fig. I. Extracts of marine phytoplankton chromatographed in iso-propanol-ammonia. A, EA fraction of sample I; B, SA fraction of sample I; C, SA fraction of sample II; D, EN fraction of sample II; E, SN fraction of sample I; F, SN fraction of sample II. IAA controls are as follows: $\mathrm{I}=\mathrm{I} \mathrm{mg} / 1 . ; 2=0 . \mathrm{I} \mathrm{mg} / 1 . ; 3=0.0 \mathrm{Img} / 1 . ; 4=0.00 \mathrm{I} \mathrm{mg} / \mathrm{l}$. Ehrlich colours are as follows: pu., purple; pk., pink; g., green; y, yellow. 
The compounds located in the EA and SA fractions show some properties in common, suggesting that in fact they may be the same compounds occurring in both fractions, existing naturally in small quantities and also released possibly from precursors in the aqueous fraction by the saponification. For example, when zone $\mathrm{Z}$ in the EA fraction is eluted and re-chromatographed

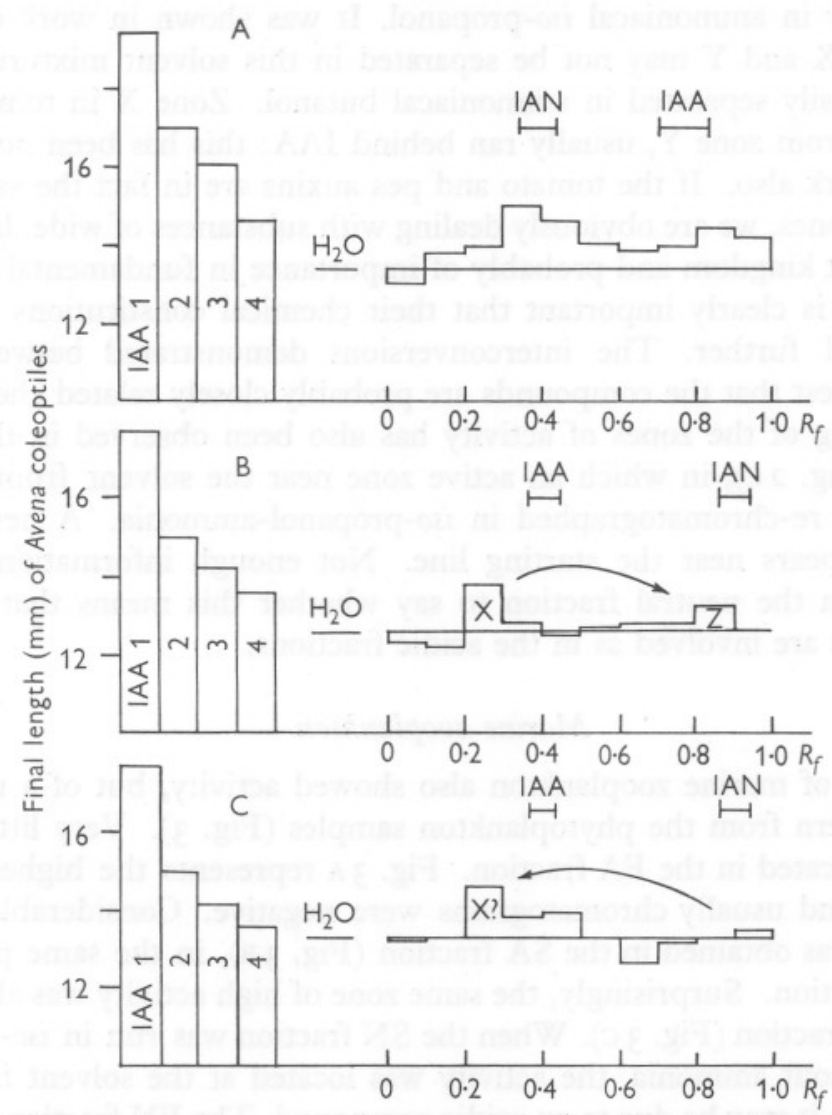

Fig. 2. Interchangeability of zones on chromatograms of marine phytoplankton. A, zone $R_{f}$ $0.8-\mathrm{I} \cdot 0$ of Fig. IA eluted and re-chromatographed in water. B, zone $R_{f} 0.2-0.6$ of Fig. IC eluted and re-chromatographed in iso-propanol-ammonia. C, zone $R_{f} 0.6-\mathrm{I} \cdot 0$ of Fig. IF eluted and re-chromatographed in iso-propanol-ammonia. IAA controls are as in Fig. I.

in water two active zones appear (Fig. $2 \mathrm{~A}$ ). When zone $\mathrm{X}$ of the SA fraction is eluted and re-chromatographed in ammoniacal $i s o$-propanol, activity appears also in zone $\mathrm{Z}$ (Fig. 2B). This interconvertibility of the zones of activity suggests that the compounds concerned are closely related chemically and exist on the paper in a state of equilibrium with each other.

The interconvertibility of $\mathrm{X}$ and $\mathrm{Z}$ may be related to a similar phenomenon observed in extracts of tomato roots, in which three compounds, $\mathrm{X}, \mathrm{Y}$, and $\mathrm{Z}$, 
were shown to be mutually interconvertible (Britton et al., I956). The same phenomenon is also reported in extracts of pea roots (Audus \& Gunning, I958), and in various pure algal cultures (Bentley, I958a). There is evidence on several of the algal chromatograms of the existence of zone $\mathrm{Y}$, though this is only transient. This may be because chromatography in the present work was usually in ammoniacal iso-propanol. It was shown in work on tomato roots that $\mathrm{X}$ and $\mathrm{Y}$ may not be separated in this solvent mixture, whereas they are easily separated in ammoniacal butanol. Zone $\mathrm{X}$ in tomato, when separated from zone Y, usually ran behind IAA: this has been noted in the present work also. If the tomato and pea auxins are in fact the same as the algal hormones, we are obviously dealing with substances of wide distribution in the plant kingdom and probably of importance in fundamental cell metabolism. It is clearly important that their chemical constitutions should be investigated further. The interconversions demonstrated between $\mathrm{X}, \mathrm{Y}$, and $\mathrm{Z}$ suggest that the compounds are probably closely related chemically.

A shifting of the zones of activity has also been observed in the neutral fraction (Fig. 2 C), in which an active zone near the solvent front has been eluted and re-chromatographed in iso-propanol-ammonia. A new zone of activity appears near the starting line. Not enough information is as yet available on the neutral fraction to say whether this means that the same compounds are involved as in the acidic fractions.

\section{Marine zooplankton}

Extracts of marine zooplankton also showed activity, but of a rather dif-ferent pattern from the phytoplankton samples (Fig. 3). Very little activity could be located in the EA fraction. Fig. $3 \mathrm{~A}$ represents the highest activity obtained, and usually chromatograms were negative. Considerable activity, however, was obtained in the SA fraction (Fig. 3 B), in the same position as the EA fraction. Surprisingly, the same zone of high activity was also located in the $\mathrm{SN}$ fraction (Fig. 3 C). When the $\mathrm{SN}$ fraction was run in iso-propanolwater, without ammonia, the activity was located at the solvent front, suggesting that it may be due to an acidic compound. The EN fraction contained no activity.

The EA and SA fractions of zooplankton sample II gave very much the same results as sample I, with a zone of activity running in the IAA position and a positive Ehrlich reaction, indicating an indole compound, at around $R_{f} 6.0$. The high activity detected in the SN fraction of sample I was not found in sample II.

\section{Sea water}

Fig 4A shows the results of bio-assay of a chromatogram of the ether fraction of the offshore sample, run in $i s o$-propanol-ammonia. There are two clear-cut zones of activity corresponding to zones $\mathrm{X}$ and $\mathrm{Z}$ located in the 


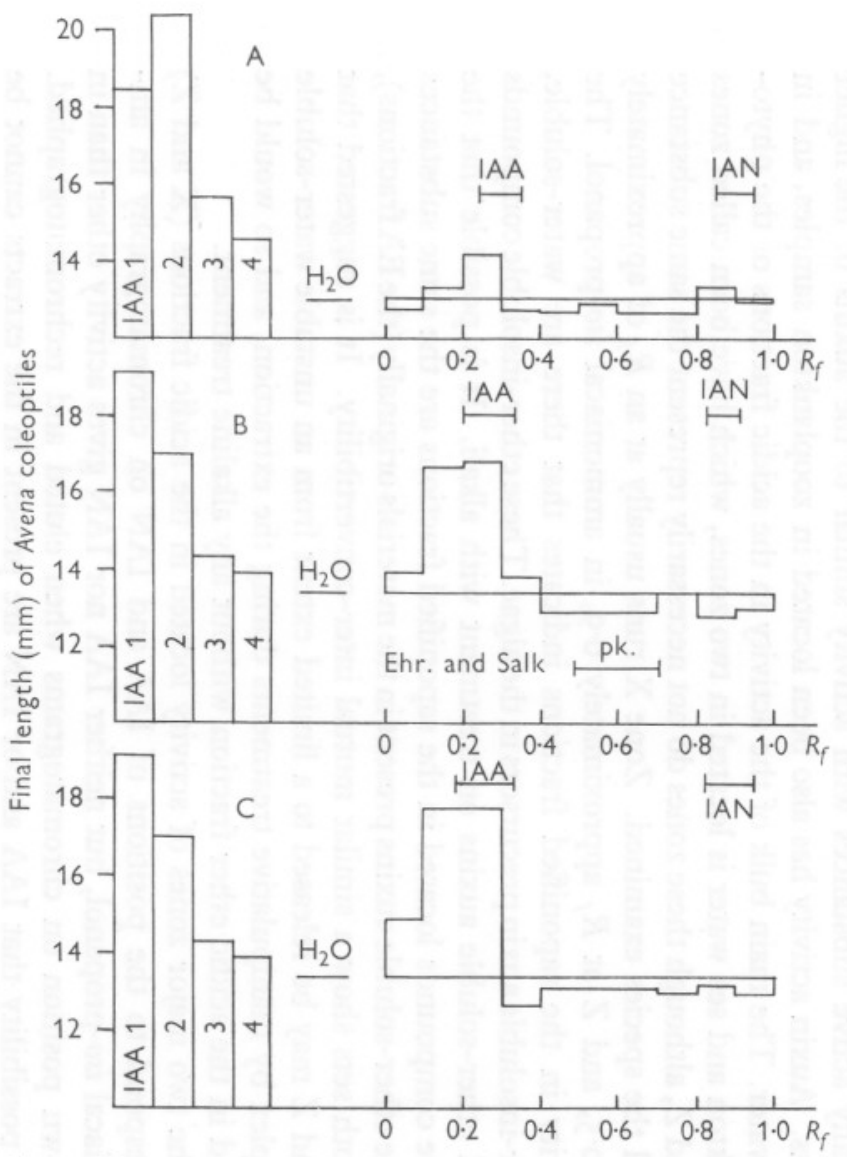

Fig. 3. Extracts of marine zooplankton chromatographed in isopropanol-ammonia. A, EA fraction of sample I; B, SA fraction of sample I; c, SN fraction of sample I. IAA controls are as in Fig. I.
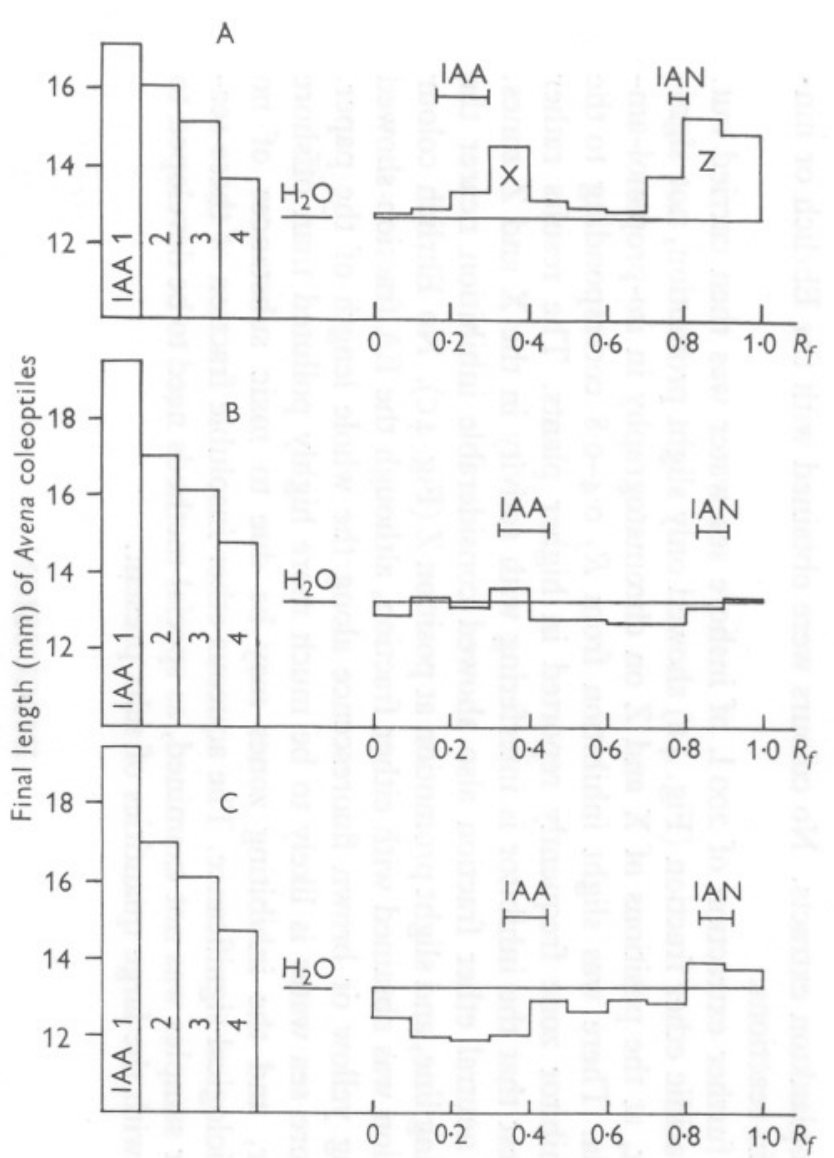

Fig. 4. Extracts of sea water chromatographed in iso-propanolammonia. A, Ether fraction of sample I; B, EA fraction of sample II; C, EN fraction of sample II. IAA controls are as in Fig. I. 
phytoplankton extracts. No colours were obtained with the Ehrlich or ninhydrin reactions.

A further extraction of 2001 . of inshore sea water was then carried out. The acidic ether fraction (Fig. 4B) showed only slight promotion, not significant, at the positions of $\mathrm{X}$ and $\mathrm{Z}$ on chromatography in iso-propanol-ammonia. There was slight inhibition from $R_{f} 0.4-0.8$ corresponding to the $\beta$-inhibitor zone frequently reported in higher plants. The results rather suggest that the inhibitor is interfering with activity in the $\mathrm{X}$ and $\mathrm{Z}$ zones. The neutral ether fraction also showed considerable inhibition nearer the starting line, and slight promotion at position Z (Fig. 4 C). No Ehrlich colour reaction was obtained with either fraction, although the EA fraction showed strong yellow or brown fluorescence along the whole length of the paper. Inshore sea water is likely to be much more highly polluted than offshore water, and the inhibiting zones may be due to toxic substances of no physiological significance. The aqueous ether-insoluble fraction of these seawater samples was not examined, as special methods need to be developed to deal with the large quantities of salts present.

\section{DISCUSSION}

The foregoing results establish that marine phytoplankton contains biologically active substances with activity similar to the auxins of the higher plants. Auxin activity has also been located in zooplankton samples, and in sea water. The main bulk of the activity in the acidic fractions of the phytoplankton and sea water is located in two zones, which have been called zones $\mathrm{X}$ and $\mathrm{Z}$, although these zones do not necessarily represent the same substance in all the species examined. Zone $\mathrm{X}$ runs usually at an $R_{f}$ of approximately $0.3-0.5$, and $\mathrm{Z}$ at $R_{f}$ approximately 0.9 , in ammoniacal iso-propanol. The activity in the saponified fractions indicates that there are water-soluble, ether-insoluble auxin precursors in the algae. These ether-insoluble compounds yield ether-soluble auxins on treatment with alkali. It is possible that the active compounds located in the saponified fractions are the same substances as the ether-soluble auxins present in the materials originally (theEA fractions), as both sets show a similar mutual inter-convertibility. It is suggested that $\mathrm{X}$ and $\mathrm{Z}$ may be released to a limited extent from an unstable water-soluble complex by manipulative treatments during the extraction, and so would be found in the acidic ether fraction without any alkaline treatment.

The two major zones of activity located in the acidic fractions ( $\mathrm{X}$ and $\mathrm{Z}$ ) correspond to the positions of IAA and IAN on chromatography in ammoniacal iso-propanol, but neither IAA nor IAN gives activity other than in its own position on chromatograms when eluted and rechromatographed. The possibility that IAA and/or IAN are present in the extracts cannot be dismissed, since biological activity is obtained at the position of these com- 
pounds in both ammoniacal iso-propanol and water. One must conclude, however, that other compounds (referred to in this work as $\mathrm{X}$ and $\mathrm{Z}$ ) are also present in these active zones, since they show a mutual inter-convertibility which is not shown by IAA and IAN.

The total amount of auxins (zones $\mathrm{X}$ and $\mathrm{Z}$ ) located in the offshore sea water, calculated in terms of the IAA controls bio-assayed in the same experiment, is $0.375 \mu \mathrm{g}$ in 1101 . (0.06 $\mu \mathrm{g}$ in zone $\mathrm{X}$ and $0.315 \mu \mathrm{g}$ in zone $\mathrm{Z}$ ). An improvement in the growth of a marine diatom, Skeletonema costatum, under the influence of IAA at a concentration of $10^{-11}$ to $10^{-10} \mathrm{~g} / \mathrm{ml}$. has been noted (Bentley, I958a). This is equivalent to $\mathrm{I}-10 \mu \mathrm{g}$ in 1001 . Thus the amount of auxin detected in sea water is approximately ten times less than would be needed to have an optimum effect on the growth of Skeletonema. It should be borne in mind, however, that the amounts of auxin finally detected by bio-assay of extracts are probably much less than those present in the original materials due to losses in the many stages of purification and assay.

The investigations reported in this article have been carried out during the tenure of a Senior Government Research Fellowship, and I am indebted to the Director of the Department of Agriculture and Fisheries for Scotland Marine Laboratory for facilities for the work.

\section{SUMMARY}

Extracts of marine phytoplankton, marine zooplankton and sea water have been examined for plant hormones of the auxin type. The phytoplankton consisted predominantly of diatoms, in particular of Leptocylindrus danicus, Chaetoceros debilis and $C$. decipiens. The zooplankton consisted predominantly of copepods, in particular Temora, Calanus stages I-IV and Para/ Pseudocalanus. The samples were extracted chemically and the extracts split into acidic and neutral components of $(a)$ the ether-soluble fractions, and (b) the ether-soluble fractions of the residue after alkaline hydrolysis. The fractions were further purified by paper chromatography in water followed by chromatography in ammoniacal iso-propanol. They were assayed for biological activity by the Avena straight-growth test, which measures the activity of auxins in cell-enlargement.

Biological activity was detected in all phytoplankton fractions. Activity in the acidic fractions is mainly due to two hormones, tentatively called $\mathrm{X}$ and $\mathrm{Z}$. These are probably closely related chemically, as they show a mutual interconvertibility.The same two zones of activity were detected in sea water. The zooplankton samples also contained active substances. Indole compounds can be detected in the extracts, but it is not clear that the biological activity is due to indolylacetic acid or any of the known indole hormones. 


\section{REFERENCES}

Audus, L. J. \& Gunning, B. E. S., 1958. Growth substances in the roots of Pisum sativum. Physiol. Plant., Vol. II, pp. 685-97.

BentLeY, J. A., I958 $a$. Role of plant hormones in algal metabolism and ecology. Nature, Lond., Vol. I81, pp. I499-1502.

I 958 b. The naturally-occurring auxins and inhibitors. Annu. Rev. Pl. Physiol., Vol. 9, pp. 47-80.

1960a. States of auxin in the plant. Encyclopaedia of Plant Physiology, Ed. by H. Burstrom, Vol. 14, pp. 609-19. Heidelberg: Springer-Verlag. (In the Press.) 1960b. Analysis of Plant Hormones. Methods of Biochemical Analysis, Vol. 9. New York: Interscience Publishers Inc. (In the Press.)

Bentley, J. A. \& Housley, S., 1954. Bioassay of plant growth-hormones. Physiol. Plant., Vol. 7, pp. 405-I9.

Britton, G., Housley, S. \& Bentley, J. A., 1956. Chromatography of hormones in excised and intact roots of tomato seedlings. F. exp. Bot., Vol. 7, pp. 239-51.

Jepson, J. B., 1958. Indoles and related Ehrlich reactors. Chapter in Chromatographic Techniques, Clinical and Biochemical Application, Ed. by I. Smith, 309 pp. London: Heinemann.

LuCAS, C. E., 1955. External metabolites in the sea. Deep-Sea Res., Vol. 3, Suppl. Papers in Marine Biology and Oceanography, pp. 139-48.

SAUNDERS, G. W., I957. Interrelations of dissolved organic matter and phytoplankton. Bot. Rev., Vol. 23, pp. 389-409.

Stowe, B. B. \& Thimann, K.V., I954. The paper chromatography of indole compounds and some indole-containing auxins of plant tissues. Arch. Biochem., Vol. 51, pp. 499-5 I6. 